\title{
Design of Mobile Band Subsurface Antenna for Drainage Infrastructure Monitoring
}

\author{
Chan H. See ${ }^{1,2^{*}}$, Jamal Kosha ${ }^{3}$, Widad A. Mshwat ${ }^{3}$, Raed A. Abd-Alhameed ${ }^{3,4}$, Felicia L.C. Ong ${ }^{2}$, Neil J. McEwan ${ }^{3}$, \\ Peter S. Excell ${ }^{3,5}$ \\ ${ }^{1}$ School of Engineering and the Built Environment, Edinburgh Napier University, Edinburgh, EH10 5DT, UK \\ ${ }^{2}$ School of Engineering, University of Bolton, Bolton, BL3 5AB, UK \\ ${ }^{3}$ Faulty of Engineering and Informatics, University of Bradford, Bradford, BD7 1DP, UK \\ ${ }^{4}$ Information and Comm. Engineering Department, Basrah University College of Science and Technology, Basrah 24001, Iraq \\ ${ }^{5}$ Wrexham Glyndwr University, Wrexham, LL11 2AW, UK \\ *c.see@napier.ac.uk
}

\begin{abstract}
This paper presents an underground subsurface wireless sensor for drainage infrastructure water level monitoring. It operates from 800 to $2170 \mathrm{MHz}$ to cover the required GSM850/900, GSM1800/1900 and UMTS bands. The system consists of a wideband antenna, transceiver, data acquisition unit and an ultrasonic sensor. The proposed antenna is a 3-dimensional inverted double $F$ antenna and has an envelope size of $90 \times 63.5 \times 32 \mathrm{~mm}^{3}$, which is acceptably small for a cramped subsurface passageway environment. The antenna design was developed using software simulation to optimise its key parameters of return loss and radiation pattern, these being evaluated both in free space and in the partially underground environment. The design developed was then realised in hardware and tested in a representative subsurface location: a utility manhole chamber. It was found that the location of the antenna in the chamber had a significant effect on its performance, but a location that was acceptable for operational purposes was found by experiment. The overall system, including a transceiver, was demonstrated to operate satisfactorily for utility monitoring purposes, including acceptable levels of path loss for communication with mobile communication base stations.
\end{abstract}

\section{Introduction}

Deterioration of the UK's ageing drainage infrastructure due to climate change, population rise and changing patterns of demand, has resulted the associated increase in the proportion of budgets spent on maintenance present remarkable challenges to society [1]. The deterioration of sewers often involves displacement at pipe joins, which enables sewage to exit from the system (exfiltration) and ground water to enter (infiltration). Exfiltration is most likely to occur following prolonged periods of dry weather, whereas infiltration is associated with high groundwater levels. The significance of these extraneous flows is that they can create voids or zones of low soil density adjacent to the pipe that undermine the ability of the surrounding soil to support its weight, thereby enabling progressive deformation of an already deteriorating sewer. In urban areas exfiltration can lead to a significant pollution risk to groundwater resources used for raw water supply. Infiltration can lead to increased flood risk and enhanced load at downstream wastewater treatment plants thereby increasing energy use and other costs associated with wastewater treatment. To combat this problem, it is imperative for engineers and scientists to make use of technological advances, which will allow them to monitor, sense, record and better comprehend the behaviour of this engineering system under both normal and extreme operating conditions.

In recent years, due to advance of digital technologies, low cost sensing research has been undergoing a massive revolution, promising to have significant impacts on a diverse range of applications relating to the environment, national security, food, energy, and utility networks. Wireless Sensor Networks (WSN) have received significant research attention due to their very wide range of applications in business, transportation, government, healthcare and the military. Many aspects of WSN design, including network architectures, protocols, signal processing and hardware, have been intensively investigated for communications and sensing in internet of underground things [2-10]. The convergence of the Internet, telecommunications, and novel information technologies with viable techniques for miniaturization now offers immense opportunities for the development and application of sensor systems to meet these unabated needs. This is particularly evident in the urban environment where a range of communication technologies such as GPRS, WiFi and emerging wireless broadband standards (such as 5G) are available. It is therefore the objective of this paper to demonstrate how a large number of small and low-cost sensors can be utilized and integrated into the sewerage infrastructure to improve its performance and prolong its lifetime usage, while continuously evaluating and managing risks and uncertainties.

This paper presents the design, development and implementation concepts of a subsurface wireless water level monitoring system which is installed underneath a manhole cover. In section II, the parts of the system will be introduced. Simulated and experimental findings will be illustrated and 
discussed in section III. Finally, conclusions are drawn in section IV.

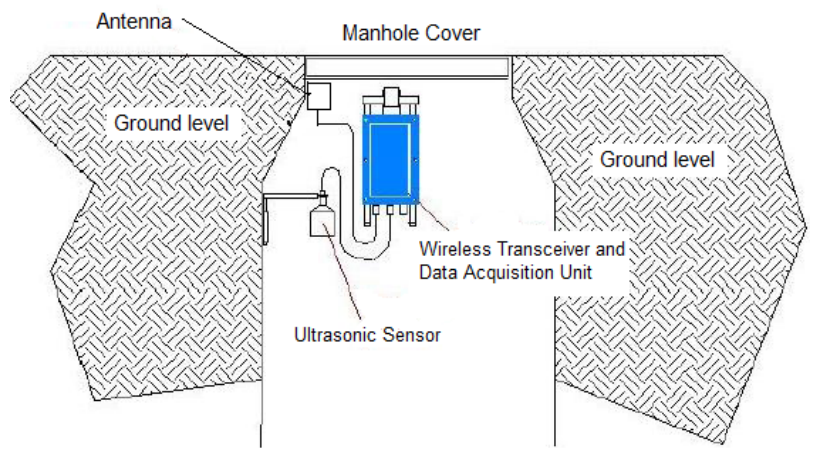

Fig. 1. Proposed Mobile Band Subsurface Wireless Sensor
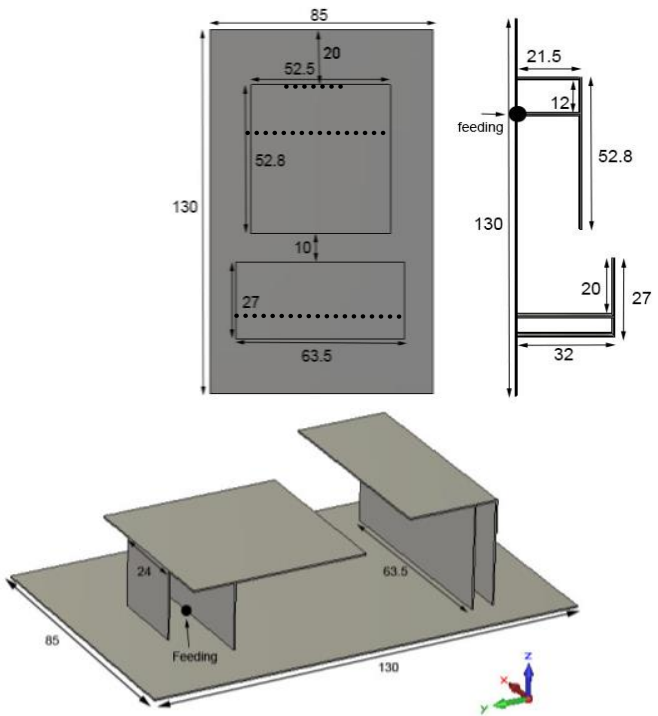

Fig. 2. Proposed Antenna Geometry. Top: top and side views, bottom is auxiliary view

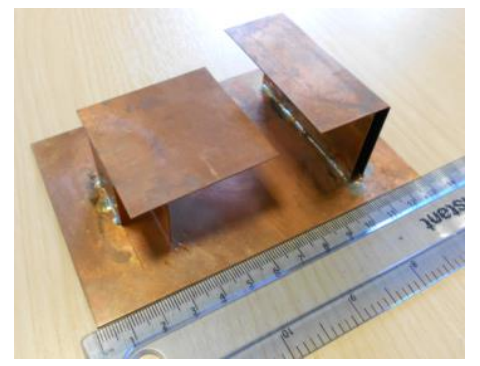

Fig. 3. Practical Prototype of the proposed antenna

\section{System Design AND ConceptS}

Fig. 1 shows the proposed ultrasonic wireless sensor system. To avoid trip hazards and attracting vandalism, this system is located below a conventional metallic manhole cover. This system is formed by an antenna, a radio module, an ATEX (explosive atmosphere) approved enclosure, a data acquisition unit, a battery and an ultrasonic sensor. It acquires data from a sensor to monitor the water level: this is linked to a data collector and transceiver in an underground WSN system to communicate with the commercial mobile networks.

\subsection{Antenna Design}

Since the antenna is required to work in a mainly lossy environment, this can change the resonance frequency and input impedance of the antenna to an extent that is dependent on the moisture content and the nature of the lossy materials, i.e. water and soil. Hence, narrowband antennas can suffer difficulties in underground applications [7, 9-10]. This motivated the choice of a wideband antenna design to assure reliable communication below ground.

A robust and unobtrusive antenna design is desirable for this application and hence a derivative of planar antenna concepts was adopted as it could be easily encased in a plastic housing. Planar antennas generally imply a structure with small extent and, in a handset application, they usually have a ground plane below the radiating elements. Bandwidth and radiation efficiency are fundamentally limited in such structures, of which the microstrip patch antenna is the prototype. Somewhat similar to this is the PIFA [11] which has advantages in handsets where it may also be considered a type of planar structure. In the present application, a manhole antenna does not operate under the extreme size constraints present in a handset and there is an opportunity to use a more open ("3-D") structure which can alleviate the problems found in handsets, especially bandwidth.

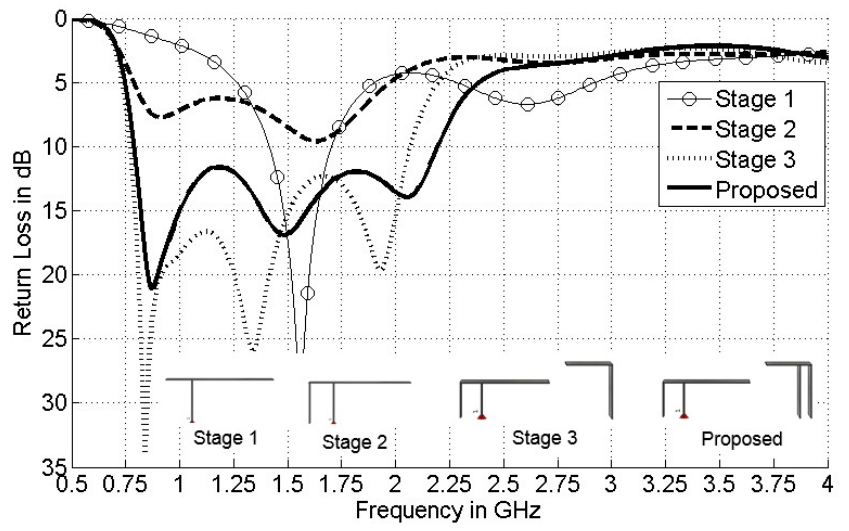

Fig.4. Evolution of the antenna design to achieve an acceptable return loss profile.

While high radiation efficiency is generally always desirable, this is not self-evidently true of gain or directivity. In a passive antenna, high peak gain can only be exploited if an effort can be made to orientate the antenna, or when the other end of the link is fortuitously in a favourable direction. 
In the context of the manhole, this question depends on whether the manhole will communicate with a randomly placed, possibly mobile, transceiver, or will be used in a fixed link. Even in the latter case, orientating the antenna during installation may be considered unrealistic under practical conditions. For these reasons, a low-gain three-dimensional structure antenna was designed to operate in a lossy underground environment containing soil, water and rock, low gain being essential to achieve reliable communication [12]. Fig.2 illustrates the geometry of the proposed antenna, which is constituted by two inverted-F metal plates, the design being derived from the authors' previous work [13]. Hence, the antenna dimensions were initially selected based on [13] and further optimized to meet the desired characteristics [4]. To avoid dielectric loss in the substrate and maintain high radiation efficiency, this metal-made antenna was adopted instead of a printed microstrip antenna. As shown in Fig. 2, the final overall dimensions of the antenna following the design evolution were $90 \times 63.5 \times 32$ $\mathrm{mm}^{3}$ and it was mounted on a ground plane of size $85 \times 130$ $\mathrm{mm}^{2}$, the maximum dimension of the antenna itself being equivalent to 0.24 wavelengths at the centre of the lower $(800$ $\mathrm{MHz}$ ) mobile band. While this is larger than an integrated antenna in a mobile handset, it gives better signal strength in this challenging environment and the size does not cause undue blockage of the chamber. To facilitate optimisation of the system components, the antenna was connected externally to a wireless transceiver.

The methodology underlying the design evolution was the manipulation of the coupled resonances of the two inverted-F antenna elements. The parasitic inverted-F element dominates the resonance at the highest frequency but the lowest resonance is dominated by the capacitively-coupled ensemble of the two elements.To verify this design concept, the antenna assembly has been split into four stages, i.e. Stage 1 to 4 , from a top-loaded planar monopole to the proposed double inverted $\mathrm{F}$ antenna assembly. The detailed design evolution of the structure is illustrated in Fig.4. The corresponding performance of each design stage, in term of return loss across the desired operating frequency band which is from $800 \mathrm{MHz}$ to $2170 \mathrm{MHz}$ is also shown in Fig.4.

This analysis starts by considering the Stage 1 structure which is a top-loaded T-shaped monopole antenna. By optimizing the geometry parameters of this structure, the centre frequency of the required operating band, which is around $1500 \mathrm{MHz}$, can be attained with acceptable impedance matching (return loss better than $10 \mathrm{~dB}$ ) but narrow impedance bandwidth, i.e. $1400 \mathrm{MHz}$ to $1650 \mathrm{MHz}$. In order to enhance the impedance bandwidth in the upper operating frequency band, but without extending the height of the stage 1 structure, this antenna is modified by shorting one edge of the top loading plate to the ground using a metal plate, as depicted in Stage 2 of Fig.4. As a result, the modified monopole is similar to a driven PIFA and its impedance bandwidth has expanded to be in excess of 800 to $1900 \mathrm{MHz}$ for a better than $6 \mathrm{~dB}$ return loss. To further improve the impedance matching, the next step is to add an inverted L parasitic structure next to the driven PIFA with optimal coupling distance of $10 \mathrm{~mm}$. This forms the stage 3 structure in Fig.4. As can be observed, the impedance matching has been significantly improved to encompass the operating frequency band from $800 \mathrm{MHz}$ to $2050 \mathrm{MHz}$ for a better than $10 \mathrm{~dB}$ return loss. However, most of the operating frequency band now meets the criterion, except the range from $2050 \mathrm{MHz}$ to $2170 \mathrm{MHz}$ which is only $5 \mathrm{~dB}$. To further improve the impedance matching, a parasitic PIFA is used to couple the driven structure instead of the inverted-L structure. This effectively improves the impedance matching of the required band without degrading the matching of the other frequency bands.

\subsection{Ultrasonic Sensor, Transceiver, Data Acquisition Unit}

A commercial ultrasonic sensor [14] was used to detect the water level in the manhole. The working principle is based on measuring the transit time of a transmitted pulse of sound and its received echo return. Knowing that sound waves reflect from the interface between water and air due to the acoustic impedance mismatch, so that the time of flight from transmitter to receiver can be evaluated and converted into the water level. The transceiver and data acquisition units were based on a Telit HE910 cellular module [15] and Arduino processor respectively.

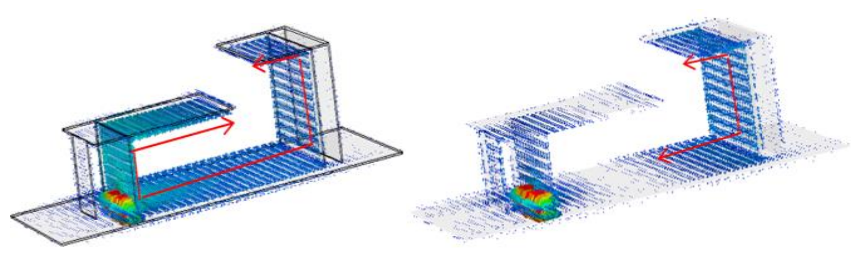

Fig. 5. Current distributions on the proposed antenna. Left: 800 MHz; Right: $2170 \mathrm{MHz}$.

\section{Results and Discussion}

The performance of the proposed antenna was initially optimized and predicted by using CST Microwave Studio [16]. To verify this design concept, the current distributions on the antenna were plotted at the low and high ends of the resonance frequencies, i.e. $800 \mathrm{MHz}$ and $2170 \mathrm{MHz}$, as shown in Fig. 5. It can be seen that the continuous current path has a total length of $185 \mathrm{~mm}$ at $800 \mathrm{MHz}$ and this equates to about $0.49 \lambda$. As is observed in Fig. 5 this lower mode is excited by the current path from the feeding plate of the driven element, via the common ground to the parasitic element, hence coupling distance is crucial here. At 2170 $\mathrm{MHz}$, the current concentrates only on the parasitic element and the current path is around $72 \mathrm{~mm}$ which is equivalent to $0.52 \lambda$. This confirms that the parasitic element determines the mode at the higher operating frequency. 
To further confirm this, a physical prototype was constructed, as shown in Fig.3. Curves for return loss, as predicted by the software model and as measured experimentally are shown in Fig. 6: the experimental measurements were conducted with a Hewlett-Packard $8510 \mathrm{C}$ vector network analyser. These curves show that resonances occurred at three frequencies: $700 \mathrm{MHz}, 1.43$ $\mathrm{GHz}$ and $2.0 \mathrm{GHz}$ in the simulation and at $800 \mathrm{MHz}, 1.45$ $\mathrm{GHz}$ and $1.95 \mathrm{GHz}$ in the measurements. Combining these resonances, the antenna exhibits an impedance bandwidth of $92.3 \%$, covering the frequency spectrum from $800 \mathrm{MHz}$ to $2170 \mathrm{MHz}$ for the criterion of return loss better than $10 \mathrm{~dB}$. Some disagreements can be found between the simulated and measured results and these can be attributed to the use of some dielectric (glue) in the prototype and fabrication errors in constructing it.

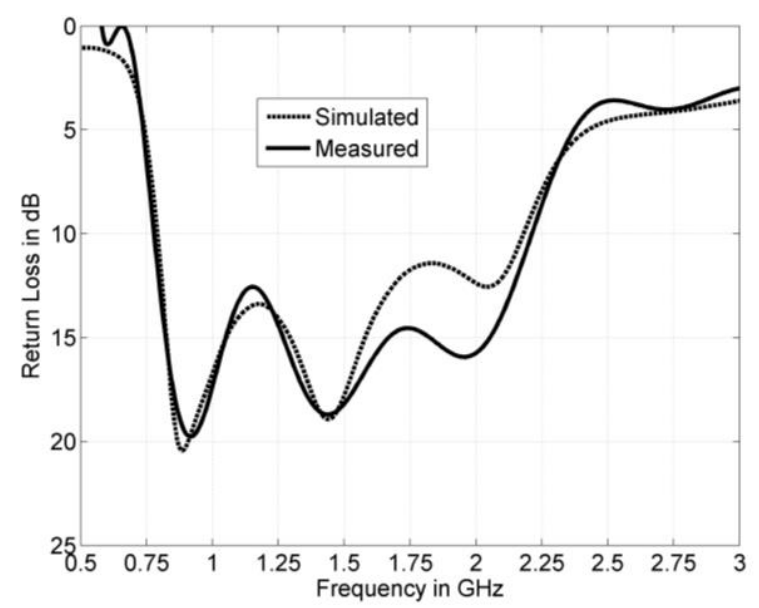

Fig.6. Simulated and measured return losses of the proposed antenna

The radiation patterns were measured in a $91 \mathrm{~m}^{3}$ rectangular anechoic chamber and are shown in Fig. 7. A calibrated broadband horn was used as the reference antenna (EMCO model 3115): this was located $4 \mathrm{~m}$ from the antenna under test (AUT). The AUT was mounted on an elevationover-azimuth positioner and the elevation axis was arranged to coincide with the polar axis of the AUT coordinate system. The radiation pattern of the prototype antenna was measured over a full circular scan of the elevation positioner, in increments of $5^{\circ}$. These pattern measurements were repeated for six representative frequencies: $825 \mathrm{MHz}, 900 \mathrm{MHz}, 960$ $\mathrm{MHz}, 1750 \mathrm{MHz}, 1960 \mathrm{MHz}$ and $2150 \mathrm{MHz}$. Fig. 7 also shows points on the patterns as computed by the simulation software. The total power for both polarizations of the antenna patterns was used to compute the radiated power flux density, i.e. the vertical and horizontal components were combined vectorially, as shown in Fig. 7. The radiation patterns are stable, consistent and nearly omnidirectional in the $\mathrm{X}$-z plane $(\phi=0)$ over the two GSM operating bands tested. The corresponding simulated and experimental peak gain and radiation efficiency can be seen in Fig. 8. As can be observed, a stable measured gain is achieved, varying between 1.3 and $1.7 \mathrm{dBi}$, over the lower band, and between 4.3 and $5.5 \mathrm{dBi}$ over the higher band. The computed and experimental gain results are effectively indistinguishable. As for the radiation efficiency, it was found that the simulated and measured results varied from $81 \%$ to $85 \%$ and $78 \%$ to $85 \%$, respectively, corresponding to averages of $83 \%$ and $81.5 \%$ over the lower band. However, over the higher band, radiation efficiencies of $84 \%$ to $96 \%$ and 83 to $92 \%$ were found for the simulated and measured results, respectively.

Table 1 gives a comparison between the performance and parameters of antennas that have previously been published for similar applications and the proposed antenna. It should be noted that most of the previous designs were intended for a single narrow band [9, 18-23], although one [25] was designed for two narrow bands and three more [10, 17, 24] for wideband operation. Only the antennas reported in references [4] and [17] were capable of covering the GSM bands required for the present application, but they were substantially larger than the design presented here.

To evaluate the radio signal strength (as detected at a cellular base station) of the proposed sensor when it is placed in a manhole, an in-situ measurement was carried out as shown in Fig. 9. As can be seen, the required equipment for this measurement are a reference broadband horn antenna positioned at a height of $1.85 \mathrm{~m}$ (to capture radiation in the direction of nearby base stations), a network analyser (model: HP 8720) and a laptop computer as a data acquisition unit. Considering the manhole metal cover as the centre point of a circle, the horizontal distance between the horn antenna and the antenna under test (AUT) was $2 \mathrm{~m}$. All of the aboveground equipment was located on a trolley and moved through eight positions surrounding the manhole cover, recording the $S_{21}$ at each position. For practical reasons, the AUT was laterally positioned near to one edge of the metal cover and then tested at varying depths of $5 \mathrm{~cm}, 15 \mathrm{~cm}$ and 25 $\mathrm{cm}$. Also, the horn was varied through vertical and horizontal orientations to check the dominant polarization of the AUT for each test position. 
Table 1 Performance Comparison with Related Previous Works

\begin{tabular}{|l|l|l|l|l|l|}
\hline Reference & Size $\left(\mathrm{mm}^{3}\right)$ & $\begin{array}{l}\text { Operating } \\
\text { Frequency } \\
\text { Bandwidth }(\mathrm{MHz})\end{array}$ & $\begin{array}{l}\text { Minimum Return } \\
\text { Loss }(\mathrm{dB})\end{array}$ & $\begin{array}{l}\text { Peak Gain } \\
(\mathrm{dBi})\end{array}$ & $\begin{array}{l}\text { Polarization/ } \\
\text { Radiation Pattern }\end{array}$ \\
\hline$[4]$ & $130 \times 130 \times 47$ & $\begin{array}{l}824-960 \\
1700-2170\end{array}$ & 10 & $\begin{array}{l}1.2-1.9 \\
4.2-5.8\end{array}$ & $\begin{array}{l}\text { Linear/ } \\
\text { Omnidirectional }\end{array}$ \\
\hline$[9]$ & $346 \times 5 \times 5$ & $433.05-434.79$ & 10 & 1.2 & $\begin{array}{l}\text { Linear/ } \\
\text { Omnidirectional }\end{array}$ \\
\hline$[10]$ & $100 \times 100 \times 0.8$ & $2000-3000$ & 10 & 5.25 & $\begin{array}{l}\text { Linear/ } \\
\text { Directional }\end{array}$ \\
\hline$[17]$ & $160 \times 160 \times 76$ & $490-3100$ & 10 & $3-6$ & $\begin{array}{l}\text { Circular/ } \\
\text { Directional }\end{array}$ \\
\hline$[18]$ & $85 \times 70 \times 2$ & $740-760$ & 10 & 3 & $\begin{array}{l}\text { Linear/ } \\
\text { Omnidirectional }\end{array}$ \\
\hline$[19]$ & $45 \times 90 \times 4$ & $902-928$ & 6 & 3 & $\begin{array}{l}\text { Linear/ } \\
\text { Omnidirectional }\end{array}$ \\
\hline$[20]$ & $650 \times 650 \times 40$ & $902-928$ & 10 & $\begin{array}{l}\text { Linear/ } \\
\text { Directional }\end{array}$ \\
\hline$[21]$ & $220 \times 220 \times 25$ & $902-928$ & 10 & 4.5 & $\begin{array}{l}\text { Linear/ } \\
\text { Directional }\end{array}$ \\
\hline$[22]$ & $650 \times 650 \times 40$ & $902-928$ & 10 & 2.13 & $\begin{array}{l}\text { Linear/ } \\
\text { Omnidirectional }\end{array}$ \\
\hline$[23]$ & $70 \times 60 \times 35$ & $950-1050$ & 10 & 2 & $\begin{array}{l}\text { Linear/ } \\
\text { Directional }\end{array}$ \\
\hline$[24]$ & $100 \times 200$ & $8000-12000$ & 10 & NA & $\begin{array}{l}\text { Linear/ } \\
\text { Directional }\end{array}$ \\
\hline$[25]$ & $51 \times 31 \times 0.2$ & $\begin{array}{l}1300-1400 \\
1750-1900\end{array}$ & $800-2170$ & 10 & $\begin{array}{l}\text { Linear/ } \\
\text { Omnidirectional }\end{array}$ \\
\hline $\begin{array}{l}\text { Design } \\
\text { proposed here }\end{array}$ & $130 \times 85 \times 32$ & & & $\begin{array}{l}\text { Linear/ } \\
\text { Omnidirectional }\end{array}$ \\
\hline & & & $1.3-5.5$ & \\
\hline
\end{tabular}
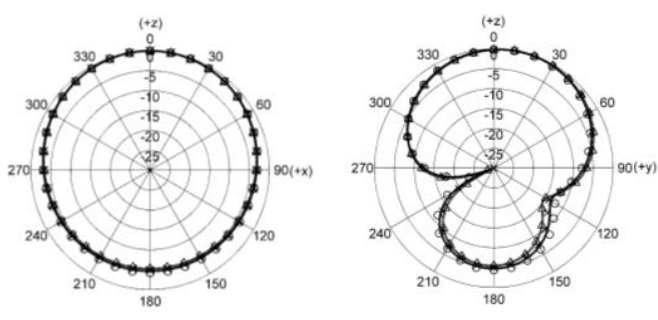

(a) Lower band
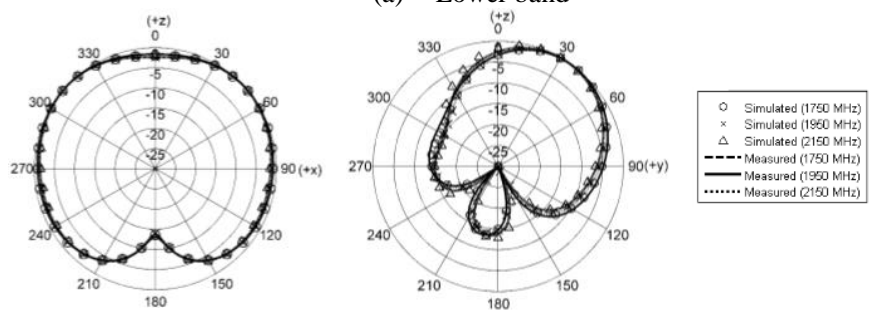

(b) Upper band

Fig. 7. Normalized radiation patterns of the proposed antenna (continuous curves: measured results; marker symbols: simulated results).

Fig. 10 shows the measured transmission coefficients $\left(\mathrm{S}_{21}\right)$ between the antenna in the manhole chamber and the external horn. It is noticeable that the vertically polarized component of this $S_{21}$ reveals that when the antenna is nearest to the ground surface (i.e. at $5 \mathrm{~cm}$ depth), the best $S_{21}$ value was found over most of the tested band, which is about $-46 \mathrm{~dB}$ for GSM900 and $-55 \mathrm{~dB}$ for GSM1800. When the antenna was positioned $25 \mathrm{~cm}$ below the ground level, the $S_{21}$ was further reduced by $-19 \mathrm{~dB}$ and $-7 \mathrm{~dB}$ to reach $-52 \mathrm{~dB}$ and -62
$\mathrm{dB}$ for the GSM900 and GSM1800 frequency bands respectively. Examining the horizontally polarized components of this antenna, the $S_{21}$ shows average values of $65 \mathrm{~dB}$ and $-60 \mathrm{~dB}$ at the three test depths for GSM900 and GSM1800 respectively. These results confirm that this antenna is operating primarily in vertical polarization mode.

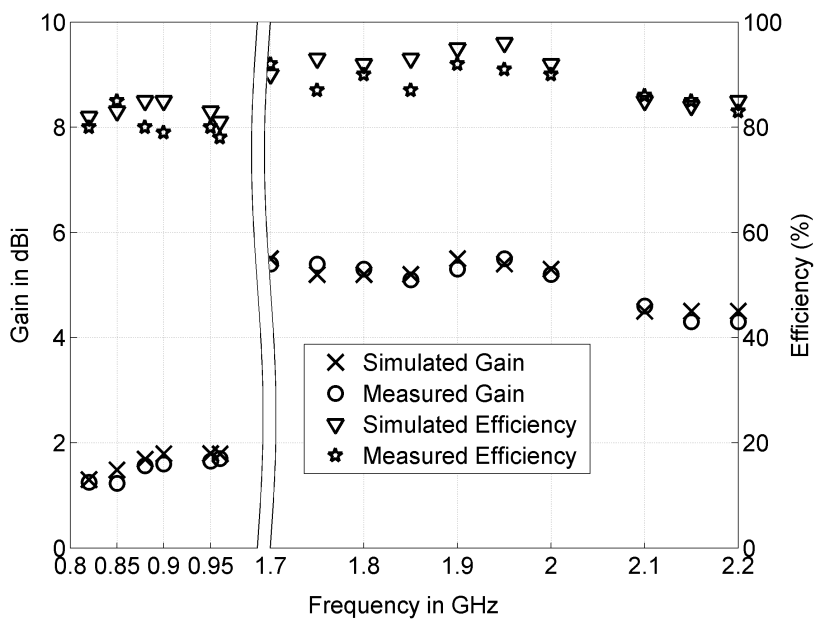

Fig. 8. Simulated and measured gain and radiation efficiency of the proposed antenna. 


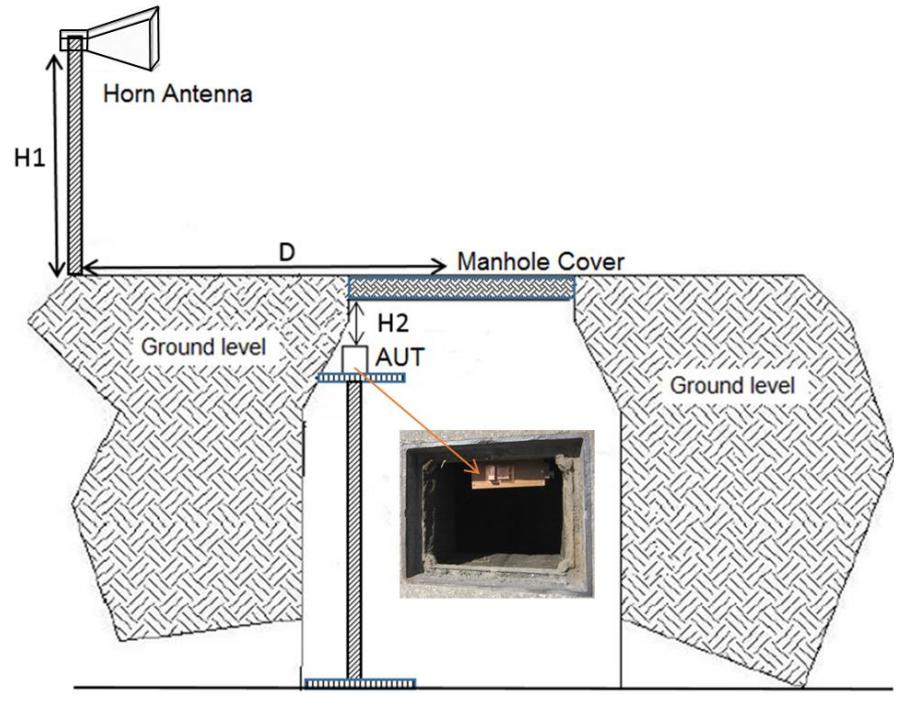

Fig. 9. On-site measurement setup, where D is $2 \mathrm{~m}$, H1 is $1.85 \mathrm{~m}$, H2 is either $5 \mathrm{~cm}, 15 \mathrm{~cm}$ or $25 \mathrm{~cm}$. AUT: Antenna under test
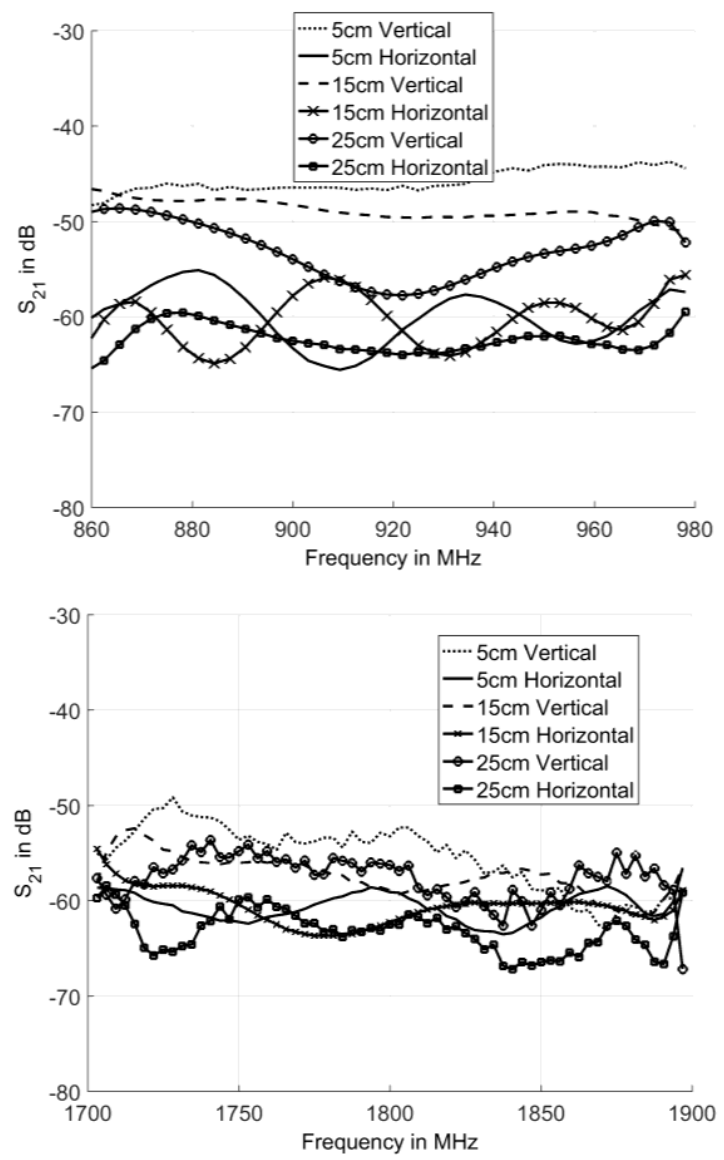

Fig. 10. Coupling $\left(S_{21}\right)$ between the reference antenna and the antenna under test (AUT) at different depths in the manhole chamber. Top: Lower band, Bottom: Upper band.

To further verify that the proposed sensor works in a real scenario, this system was installed and then monitored in a manhole chamber over a period of two months, as shown in Fig.1. In this system, the antenna model was redesigned to include a radome and wall mounting structure, as depicted in Fig.11. As can be seen, the rectangular ground plane of the antenna was printed on a circular single-sided FR4 substrate with thickness of $1.6 \mathrm{~mm}$. This substrate was located on a 1.5 $\mathrm{mm}$ thick stainless steel wall mounting bracket and a hemispherical radome was used to enclose and protect the radiating elements of the antenna. The radome material was chosen to be Polycarbonate and ABS [26], with thickness of $2.5 \mathrm{~mm}$ and dielectric constant of 3.0. The performance of this antenna in term of return loss is shown in Fig.12, together with a photograph of the radome exterior. The results clearly illustrate that introducing the radome and the wall mounting structure into the antenna model does not degrade the antenna performance. 

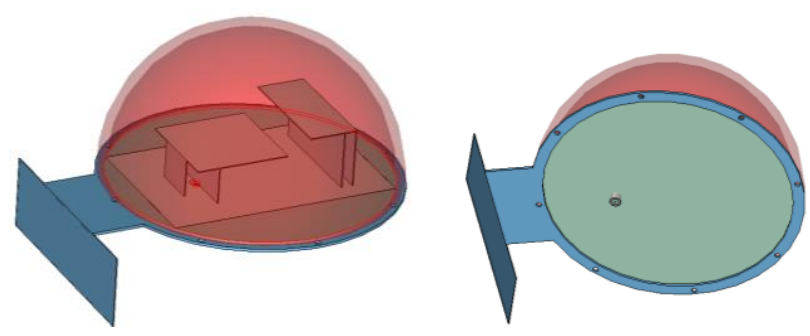

Fig. 11. Simulated antenna model with radome and wall mounting structure. Left: top view, right: bottom view

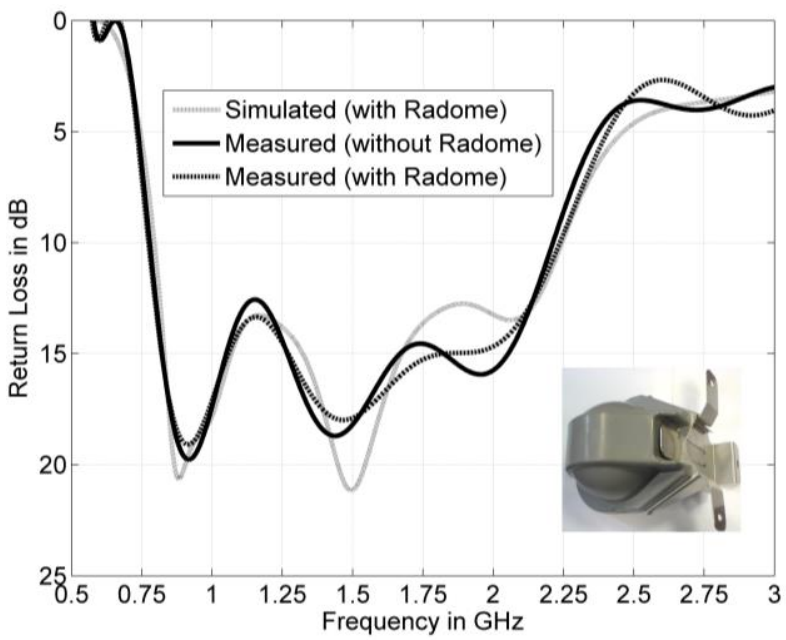

Fig. 12. Simulated and measured return losses for antenna and radome model (pictured)

To examine the received signal strength indication (RSSI) of the proposed antenna when below ground level, the antenna was installed in a real manhole at three depths $(5 \mathrm{~cm}$, $15 \mathrm{~cm}$ and $25 \mathrm{~cm}$ ), over around 3 weeks for each depth. The ultrasonic sensor and radio module were programmed to measure the water level, battery level and received signal strength every 15 minutes. This data was recorded in the SD card and sent to the remote base station via an SMS message. Selected seven-day field trial results for the three AUT depths were recorded and are plotted in Fig. 13. These measurements were carried out in dry conditions: as can be seen in Fig. 13, the water level in the manhole was as low as $5 \pm 2 \mathrm{~cm}$.

When the antenna was positioned at $5 \mathrm{~cm}$ depth, near to the manhole cover (this is the highest position at which the antenna could be installed), the RSS (received signal strength) level was found to be between -78 and $-80 \mathrm{dBm}$. However, after lowering the antenna by a further $10 \mathrm{~cm}$, the RSS level drops to around -87 to $-92 \mathrm{dBm}$. By placing the antenna another $10 \mathrm{~cm}$ lower, it is observed that the RSS level further degrades to -99 to $-102 \mathrm{dBm}$. This is very near to the minimum receiver sensitivity of the radio module which is $-109 \mathrm{dBm}$ and $-111 \mathrm{dBm}$ for GSM900 and GSM1800 bands respectively. Thus, this finding suggests the proposed antenna cannot be placed lower than $25 \mathrm{~cm}$ below the manhole cover for a reliable wireless communication link.
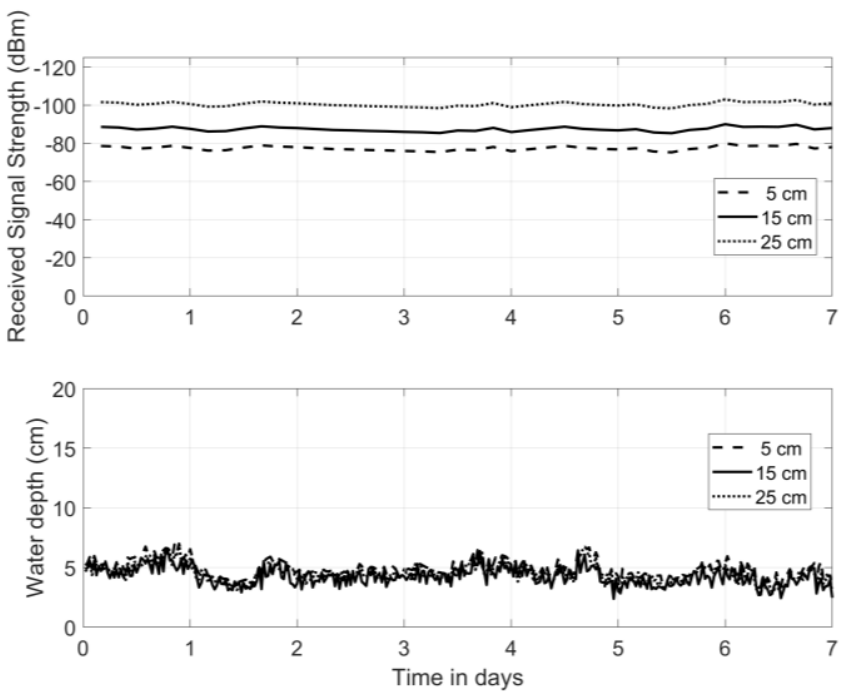

Fig. 13. Received signal strength level over time of the antenna versus the water depth in the manhole chamber at a practical site.

\section{Conclusion}

A transceiver for a subsurface underground wireless sensor for water level monitoring has been designed, investigated and implemented. To combat the signal attenuation issue in such a system, a wideband double inverted-F antenna has been proposed and discussed theoretically and experimentally. This antenna design is robust and compact, as is required for this kind of application. A wideband impedance bandwidth for this antenna was achieved by manipulating the two strongly capacitively coupled inverted-F elements: the outcome was a viable $\left(\mathrm{S}_{11}<\right.$ $-10 \mathrm{~dB}$ ) impedance bandwidth from 0.8 to $2.17 \mathrm{GHz}$. Measurements and simulations of the radiation patterns showed a good approximation to the desirable omnidirectional pattern that is needed for this kind of application: the efficiency was also shown to be very good, exhibiting less than $20 \%$ losses. To confirm the suitability of the proposed system to operate under the circumstances of a water utility environment, a field trial was performed: the system designed was subjected to a real-world test over several weeks in a challenging waste-water utility environment. The field trial results confirmed that the proposed antenna, integrated with its transceiver and located appropriately in the manhole chamber, is a viable system for use in such challenging environments.

\section{Acknowledgements}

The authors acknowledge support and funding from Yorkshire Water Services PLC and the Technology Strategy Board, via KTP Project No. 1421, "The development of a new sewerage telemetry system" and EPSRC project "Urban 
Water Systems for a Changing World," grant ref: $\mathrm{EP} / \mathrm{I029346/1.}$

\section{References}

[1] OFWAT, "Service Delivery Report 2016-17," 2018 [Online]. Available: $\quad$ https://www.ofwat.gov.uk/wpcontent/uploads/2018/01/Service-Delivery-Report-2016-17-final.pdf

[2] G-L. Huang, S-G. Zhou and T-H. Chio, "Highly-Efficient SelfCompact Monopulse Antenna System with Integrated Comparator Network for RF Industrial Applications," IEEE Trans. Ind. Electron., vol. 64, no. 1, Jan. 2017, pp. 674-681

[3] U.I. Minhas, I.H. Naqvi, S. Qaisar, K. Ali, S. Shahid and M. A. Aslam, "A WSN for Monitoring and Event Reporting in Underground Mine Environments, IEEE Systems Journal, vol.12, no.1, pp.485-496, 2018.

[4] C.H. See, R.A.Abd-Alhameed, A.A. Atojoko, N.J. McEwan and P.S. Excell, "Link Budget Maximization for a Mobile-Band Subsurface Wireless Sensor in Challenging Water Utility Environment," IEEE Trans. Ind. Electron., vol. 65, no. 1, pp. 616-625, 2018

[5] A.E. Forooshani, A.A. Lotfi-Neyesanak, D.G. Michelson, "Optimization of Antenna Placement in Distributed MIMO Systems for Underground Mines", IEEE Trans. Wireless Communications, vol.13, no.9, pp.4685-4692, 2014

[6] S-L. Lin, A.A. Alshehri, P. Wang and I.F. Akyildiz, "Magnetic Induction-Based Localization in Randomly Deployed Wireless Underground Sensor Networks," IEEE Internet of Things Journal, vol.4, no.5, pp.1454-1465, 2017.

[7] C.H. See, K.V. Horoshenkov, R.A. Abd-Alhameed, Y.F. Hu and S.J. Tait, "A Low Power Wireless Sensor Network for Gully Pot Monitoring in Urban Catchments", IEEE Sensors Journal, vol.12, no. 5, pp.1545-1553, May 2012.

[8] G.Lui, Z.Wang and T. Jiang, "QoS-Aware Throughput Maximazation in Wireless Powered Underground Sensor Networks," IEEE Trans. Communications," vol. 64, no. 11, pp.4776-4789, 2016.

[9] H. Kunsei, K.S. Bialkowski, M. S. Alam, A.M. Abbosh, "Improved Communications in Underground Mines Using Reconfigurable Antennas," IEEE Trans. Antennas and Propagation, vol.66, no. 12, pp.7505-7510, Dec. 2018

[10] A.Salam, M. C. Vuran, X. Dong, C.Argyropoulos and S. Irmak, "A Theoretical Model of Underground Dipole Antennas for Communications in Internet of Underground Things," IEEE Trans. Antennas and Propagation, 2019 (in press, Early Access)

[11] Y. Liu, Y-M. Zhou, G-F. Liu and S-X. Gong, "Heptaband Inverted-F Antenna for Metal Rimmed Mobile Phone Applications," IEEE Antennas and Wireless Propagation Letters, Vol.15, pp.996-999, 2016

[12] C. Zhou, T. Plass, R. Jacksha and J. A. Waynert, "RF Propagation in Mines and Tunnels," IEEE Antennas \& Propagation Magazine, vol.57, no.4, pp.88-102, 2015.

[13] C.H.See, R.A. Abd-Alhameed, D.Zhou, H.I.Hraga and P.S Excell, "Compact Multiple Input and Multiple Output/Diversity Antenna for Portable and Mobile Ultra-wideband applications," IET Microwaves, Antennas \& Propagation, vol. 7, pp.444-451, April 2013

[14] Hawkeye Ultrasonic level sensor, aailable: http://www.ietg.co.uk/products/hawkeye-2-sewer-level-monitoring/

[15] Telit HE910 Cellular radio module, available: http://www.telit.com/fileadmin/user upload/products/Downloads/3G/x e910/Telit HE910 Hardware User Guide r27.pdf

[16] Computer Simulation Technology GmBH, [online] Available: http://www.cst.com.

[17] T.W. Hertel and G.S. Smith, "The Conical Spiral Antenna over the Ground", IEEE Trans. Antennas and Propagation, vol.50, no.12, pp.1668-1675, December 2002.

[18] D. Trinchero and R. Stefanelli, "Microwave Architectures for Wireless Mobile Monitoring Networks inside Water Distribution Conduits,"
IEEE Trans. Microwave Theory and Techniques, vol.57, no.12, pp.3298-3306, 2009.

[19] A.S. Kesar and E. Weiss, "Wave Propagation between Buried Antennas", IEEE Trans. Antennas and Propagation, vol.61, no.12, pp.6153-6156, April 2013.

[20] J.F. Mastarone and W.J. Chappell, "Urban Sensor Networking Using Thick slots in Manhole covers," IEEE Antennas and Propagation Society International Symposium, pp.779-782, 2006

[21] S. Jeong, D. Ha, M.M. Tentzeris, "A Cavity-backed Slot Antenna with High Upper Hemisphere Efficiency for Sewer Sensor Network," IEEE Antennas and Propagation Society International Symposium (APSURSI), pp.49-50, 2013

[22] S. Jeong and W.J. Chappell, "Adaptive composite antennas for a citywide sensor network," IET Microwaves. Antennas and Propagation, vol.4, no.11, pp.1916-1926, 2010

[23] R-Y. Chao and K-S. Chung, "A Low Profile Antenna Array for Underground Mine Communication," Singapore ICCS '94. Conference Proceedings., vol.2, pp.702-709, 1994

[24] W. Tang, Y. Hao, "Cloak on Underground Antenna Using Transformation Electromagnetics," IEEE International Symposium on Antennas and Propagation (APS/URSI), pp.2865-2868, 2011.

[25] P. Soontornpipit, C.M. Furse, Y.C. Chung and B.M. Lin, "Optimization of a Buried Microstrip Antenna for Simultaneous Communication and Sensing of Soil Moisture", IEEE Trans. Antennas and Propagation, vol.54, no.3, pp.797-800, 2006.

[26] Covestro AG, Leverkusen, Germany, Bayblend T65 XF polycarbonate, available:

https://www.plastics.covestro.com/en/Products/Bayblend/ProductList/2 01709120459/Bayblend-T65-XF 